\title{
Assessment of visual sensation, psychiatric profile and quality of life following vestibular schwannoma surgery in patients prehabituated by chemical vestibular ablation
}

\author{
Zuzana Balatkovaa , Zdenek Cada a, Silvie Hruba ${ }^{a}$, Martin Komarc ${ }^{b}$, Rudolf Cernyc
}

\begin{abstract}
Aims. Preoperative chemical vestibular ablation can reduce vestibular symptoms in patients who have gone through vestibular schwannoma resection. The goal of this study was to determine whether chemical vestibular prehabituation influences the patients' post-operative perception of visual stimulation, mental status and quality of life. We also tried to find out whether increases of optokinetic nystagmus, measured by routine electronystagmography, correlate with subjective symptoms.

Methods. We preoperatively administered ( 2 months prior to surgery) $0.5-1.0 \mathrm{~mL}$ of $40 \mathrm{mg} / \mathrm{mL}$ nonbuffered gentamicin in three intratympanic instillations in 11 patients. Head impulse and caloric tests confirmed reduction of vestibular function in all patients. The control group consisted of 21 patients. Quality of life in both groups was evaluated using the Glasgow Benefit Inventory, the Glasgow Health Status Inventory and the Dizziness Handicap Inventory questionnaires. Visual symptoms and optokinetic sensation were evaluated using a specific questionnaire developed by our team and by measuring gains preoperatively and postoperatively in both groups using routine electronystagmography. The psychological profile was evaluated using the Zung Self-Rating Depression Scale and the Generalised Anxiety Disorder Assessment questionnaires.
\end{abstract}

Results. There were no statistically significant differences between both groups with regards to the results of the questionnaires. Patients who received preoperative gentamicin were less sensitive to visual stimulation $(P<0.10)$ and many of them had a significantly higher gain in the optokinetic nystagmus than the control group in the preoperative stage. Conclusion. Pre-treatment with gentamicin helps to lower anxiety levels in patients and improves their general postoperative status. Pre-treated patients are also less sensitive to optokinetic stimulation.

Trial Registration: ClinicalTrials.gov, NCT03638310.

Key words: vestibular prehabituation, vestibular schwannoma, optokinetic stimulation, anxiety, depression

Received: June 24, 2019; Revised: November 3, 2019; Accepted: November 4, 2019; Available online: December 3, 2019 https://doi.org/10.5507/bp.2019.056

(c) 2020 The Authors; https://creativecommons.org/licenses/by/4.0/

${ }^{a}$ Department of Otorhinolaryngology and Head and Neck Surgery, $1^{\text {st }}$ Faculty of Medicine Charles University in Prague and Motol University Hospital, Postgraduate Medical School, Prague, Czech Republic

${ }^{b}$ Department of Anthropomotorics and Methodology, Faculty of Physical Education and Sport, Charles Univerzity in Prague, Czech Republic 'Department of Neurology, $2^{\text {nd }}$ Faculty of Medicine, Charles University in Prague and Motol University Hospital, Prague, Czech Republic Corresponding author:Zdenek Cada, e-mail:zdenek.cada@lf1.cuni.cz

\section{INTRODUCTION}

Surgery of the vestibular schwannoma causes acute peripheral vestibular syndrome in the postoperative pe$\operatorname{riod}^{1-4}$. It is generally known that vertigo is the dominant syndrome in the postoperative stage. Vestibular rehabilitation plays a key role in central compensation ${ }^{5-7}$, which lasts several weeks. Age, rate of preoperative labyrinth dysfunction, size of tumour, and internal, psychiatric and neurological comorbidities are factors which influence the process of compensation. Prehabituation by chemical peripheral vestibular ablation with gentamicin is one of the methods used to accelerate compensation. This procedure preoperatively decreases labyrinth function and allows for faster compensation in the postoperative period $^{8}$. Sensitivity to visual stimulus and optic flow is one of the symptoms described in the literature ${ }^{8,9}$, which occurs after an acute peripheral vestibular lesion. In the Cada study (2016), the gentamicin-treated patient group was significantly less sensitive to optic flow stimulation than the control group, respective to the "supermarket syndrome". Optic flow is a type of three-dimensional optokinetic stimulation important for posture and balance perception and is very important for quality of life and space and motion perception. The causal relationship between balance and anxiety has been clinically proven. Vestibular stimulus increases anxiety levels, and on the other hand, anxiety worsens balance function and quality of life $\mathrm{e}^{10-12}$.

Mental state can be evaluated by clinical examination or subjectively using validated questionnaires, for example the Generalised Anxiety Disorder Assessment (GAD-7) (ref. ${ }^{13,14}$ ) and Zung Self-Rating Depression Scale (ZUNG) (ref. ${ }^{15}$ ). GAD-7 evaluates anxiety and the ZUNG questionnaire is focused on symptoms of depression. Health 
Table 1. Patient characteristics.

\begin{tabular}{|c|c|c|c|c|c|c|c|}
\hline Group & Patient & Sex & $\begin{array}{c}\text { Age } \\
\text { (years) }\end{array}$ & Side & $\begin{array}{c}\text { Hearing } \\
\text { (Gardner- } \\
\text { Robertson) }\end{array}$ & $\begin{array}{l}\text { Size of } \\
\text { tumour } \\
(\text { Koos) }\end{array}$ & $\begin{array}{c}\text { Calorization } \\
\text { (side difference) } \\
(\%)\end{array}$ \\
\hline \multirow{11}{*}{$\begin{array}{l}\text { Gentamicin } \\
\text { group }\end{array}$} & 1 & $\mathrm{~F}$ & 46 & $\mathrm{~L}$ & IV & 2 & 24 \\
\hline & 2 & $\mathrm{~F}$ & 35 & $\mathrm{R}$ & III & 4 & 10 \\
\hline & 3 & M & 40 & $\mathrm{R}$ & III & 4 & 17 \\
\hline & 4 & M & 37 & $\mathrm{R}$ & II & 4 & 22 \\
\hline & 5 & $\mathrm{~F}$ & 67 & $\mathrm{R}$ & II & 4 & 13 \\
\hline & 6 & M & 45 & $\mathrm{R}$ & IV & 4 & 25 \\
\hline & 7 & $\mathrm{~F}$ & 51 & $\mathrm{~L}$ & IV & 4 & 58 \\
\hline & 8 & $\mathrm{~F}$ & 58 & $\mathrm{R}$ & III & 2 & 33 \\
\hline & 9 & M & 58 & $\mathrm{R}$ & III & 2 & 21 \\
\hline & 10 & M & 32 & $\mathrm{R}$ & IV & 2 & 16 \\
\hline & 11 & $\mathrm{M}$ & 63 & $\mathrm{R}$ & III & 4 & 26 \\
\hline \multirow{21}{*}{$\begin{array}{l}\text { Control } \\
\text { group }\end{array}$} & 1 & $\mathrm{~F}$ & 50 & $\mathrm{~L}$ & $\mathrm{~V}$ & 3 & 30 \\
\hline & 2 & $\mathrm{~F}$ & 39 & $\mathrm{R}$ & I & 3 & 18 \\
\hline & 3 & $\mathrm{~F}$ & 48 & $\mathrm{~L}$ & III & 4 & 25 \\
\hline & 4 & $\mathrm{~F}$ & 49 & $\mathrm{R}$ & I & 2 & 21 \\
\hline & 5 & M & 54 & $\mathrm{~L}$ & III & 4 & 25 \\
\hline & 6 & M & 32 & $\mathrm{R}$ & II & 3 & 17 \\
\hline & 7 & $\mathrm{~F}$ & 20 & $\mathrm{R}$ & IV & 4 & 39 \\
\hline & 8 & $\mathrm{~F}$ & 33 & $\mathrm{~L}$ & I & 3 & 25 \\
\hline & 9 & $\mathrm{~F}$ & 37 & $\mathrm{R}$ & IV & 4 & 17 \\
\hline & 10 & $\mathrm{M}$ & 35 & $\mathrm{~L}$ & II & 2 & 0 \\
\hline & 11 & $\mathrm{~F}$ & 43 & $\mathrm{R}$ & II & 2 & 10 \\
\hline & 12 & $\mathrm{~F}$ & 61 & $\mathrm{R}$ & II & 2 & 18 \\
\hline & 13 & $\mathrm{~F}$ & 62 & $\mathrm{~L}$ & II & 4 & 30 \\
\hline & 14 & $\mathrm{~F}$ & 48 & $\mathrm{~L}$ & I & 4 & 35 \\
\hline & 15 & $\mathrm{~F}$ & 54 & $\mathrm{~L}$ & II & 4 & 16 \\
\hline & 16 & $\mathrm{M}$ & 24 & $\mathrm{~L}$ & II & 4 & 12 \\
\hline & 17 & $\mathrm{M}$ & 48 & $\mathrm{R}$ & III & 4 & 4 \\
\hline & 18 & $\mathrm{M}$ & 35 & $\mathrm{R}$ & II & 2 & 21 \\
\hline & 19 & $\mathrm{M}$ & 44 & $\mathrm{~L}$ & III & 4 & 14 \\
\hline & 20 & $\mathrm{~F}$ & 63 & $\mathrm{R}$ & IV & 4 & 25 \\
\hline & 21 & $\mathrm{~F}$ & 48 & $\mathrm{~L}$ & IV & 4 & 38 \\
\hline
\end{tabular}

status after surgery and quality of life were measured by the validated Glasgow Benefit Inventory (GBI) $\left(\right.$ ref. $\left.^{8}\right)$, the Glasgow Health Status Inventory (GHSI) (ref. ${ }^{16}$ ) and the Dizziness Handicap Inventory (DHI) $\left(\right.$ ref. $\left.{ }^{17}\right)$.

In this study, we aimed to determine whether chemical vestibular prehabituation influences the patients' postoperative perception of visual stimulation, mental status and quality of life. We also tried to find out whether optokinetic nystagmus gain, measured by routine electronystagmography, correlates with subjective symptoms.

\section{MATERIALS AND METHODS}

\section{Patients}

The study consisted of 32 patients ( 13 males, 19 females, mean age 47.12, range 20-67 years) who underwent surgical treatment for vestibular schwannoma utilizing the retrosigmoid approach during the period from 2015 to 2017 (Table 1). Patients were preoperatively examined by ENT specialists and were indicated for surgery. In a head impulse test, none of the patients had preoperatively positive saccades. We preoperatively evaluated hearing in all patients, according to the Gardner and Robertson classification system. Patients with serviceable hearing were preferentially included in the control group, the only exception being patients with large T4 tumors, in whom the probability of hearing preservation was low and who decided themselves to undergo the gentamicin treatment. Therefore, the distribution of patients into groups was not strictly random, due to ethical concerns. We also were bound to respect the choice of the patient. All hearingimpaired patients were informed about the potential risk of hearing loss after the surgery. Gain in optokinetic nystagmus with stimulus velocities of $10,20,30,40$, and $50^{\circ}$ per second were calculated from routine electronystagmographic tests preoperatively. Spontaneous nystagmus, subjective visual vertical test (SVV) and caloric tests were also performed on all patients preoperatively (time I). Patients were divided into the gentamicin group (11 patients, 5 females, 6 males) and control group ( 21 patients, 14 females, 7 males). 
Table 2. Additional questions 1-9.

1. Do you have instability with, or does faster rotational motion bother you (e.g. rotating head from side to side when crossing the road)?

2. Do you have instability with, or does walking on uneven surfaces bother you (e.g. walking up the stairs / walk in the snow)?

3. Do you have instability with, or does quickly changing position bother you (e.g. lying on a bed / getting up / recumbent)?

4. Do you have instability with, or does walking in darkness / twilight bother you?

5. Do you have instability with, or does reading while driving bother you (e.g. the ability to keep eyes when walking)?

6. Do you have instability with, or does shopping in a supermarket bother you (e.g. rapid changes in products on the shelves)?

7. Do you have instability with, or does a greater amount of auditory and visual sensation bother you (e.g. shopping malls)?

8. Do you have instability with, or does reading for a long time bother you?

9. Do you have instability with, or does watching TV bother you?

Two months before the date of surgery, the gentamicin group received a 3 trans-tympanic injections of $0.5-1.0$ $\mathrm{mL}$ of nonbuffered gentamicin $(40 \mathrm{mg} / \mathrm{mL})$ until the head impulse test was positive. The period between each dose was 2 to 3 weeks, and all patients experienced significant vestibular function loss after the third instillation of antibiotics. Both groups were instructed to practice home balance exercises (standing on a foam surface, weight shifting, training gait with head movements etc.). Two weeks before surgery, an optokinetic test was administered (time II) and gains were noted as well as SVV test and spontaneous nystagmus in the gentamicin group. The same tests were also performed in both groups, at 2 weeks (time III) and 3 months (time IV) postoperatively.

Patients were required to complete ZUNG, GAD, DHI, GBI and GHSI questionnaires 2 months preoperatively (time 1), two weeks before the surgery and after gentamicin instillation (time 2), and 3 months postoperatively (time 3 ). Questionnaires were translated into the Czech language. We also used an additional questionnaire (nine questions, Table 2), based on the most frequent complaints presenting in our clinical practice (administered in Czech). Patients completed this additional questionaire ${ }^{9}$ during time 1 ( 2 months preoperatively), time 3 (3 months after the surgery) and in time 4 (12 months postoperatively).

\section{Questionnaires}

The same questionnaires we used in our previous study were used for this study ${ }^{9}$. The GBI questionnaire contains 18 questions. Responses are based on a five-point Likert scale. It ranges between different rates of deterioration or improvement of the patient's health status. In the GBI questionnaire, a total score is evaluated, as well as other three subscales: a general subscale (12 questions), a social support subscale (three questions), and a physical health subscale (three questions). The score can range from -100 to +100 . The score " 1 " corresponds to the worst change in health status and " 5 " corresponds with the best change in health status.

The GHSI questionnaire consists of 18 questions. A five-point Likert scale ranging from high to low con- cerning health status was used. A total score and three subscales were calculated: general, social, and physical health subscales. Total scores range from 0 to +100 . For each question, the score of " 1 " describes the patients' most negative health status and the score of " 5 " describes the most positive health status possible ${ }^{16}$.

The DHI consists of 25 items and the score ranges from 0 to +100 . The higher score is, the more severe of a handicap it represents ${ }^{17}$.

The additional questionnaire (Table 2) was developed by neurootologists from the Department of Otorhinolaryngology and Head and Neck Surgery of the $1^{\text {st }}$ Faculty of Medicine, Charles University in Prague and the Motol University Hospital. Scores for each question range from 1 to 4 . Higher scores correspond to a more severe handicap. Statistical comparison was performed between the gentamicin and control group for all questions.

Generalised Anxiety Disorder Assessment (GAD-7) is a questionnaire used for screening panic, social and post-traumatic anxiety disorders. Each question is scored on a range from 0 to 3 . Total scores of 5, 10, and 15 are taken as the cut-off points for mild, moderate and severe anxiety ${ }^{14}$.

The Zung Self-Rating Depression Scale (ZUNG) is a questionnaire focused on the patient's level of depression. It consists of 20 items rating the affective, psychological and somatic symptoms associated with depression. Each question is scored on a scale of 1 through 4 . Total scores above 44 are considered abnormal ${ }^{15}$.

\section{Statistical analysis}

Basic descriptive statistics (mean, median, confidence interval, standard deviation, interquartile range, skewness, and kurtosis) were computed for all variables, which were then tested for normality using Shapiro-Wilk tests. Differences in analyzed variables (age, size of tumour, GHSI-total and sub-scale scores, GBI-total and sub-scale scores, DHI scoring, GAD-7 scoring, ZUNG scoring, the nine additional questions, optokinetic gain) were examined using nonparametric statistical tests, given the relatively small number of observations in our sample. Specifically, we used the Mann-Whitney U test and the 


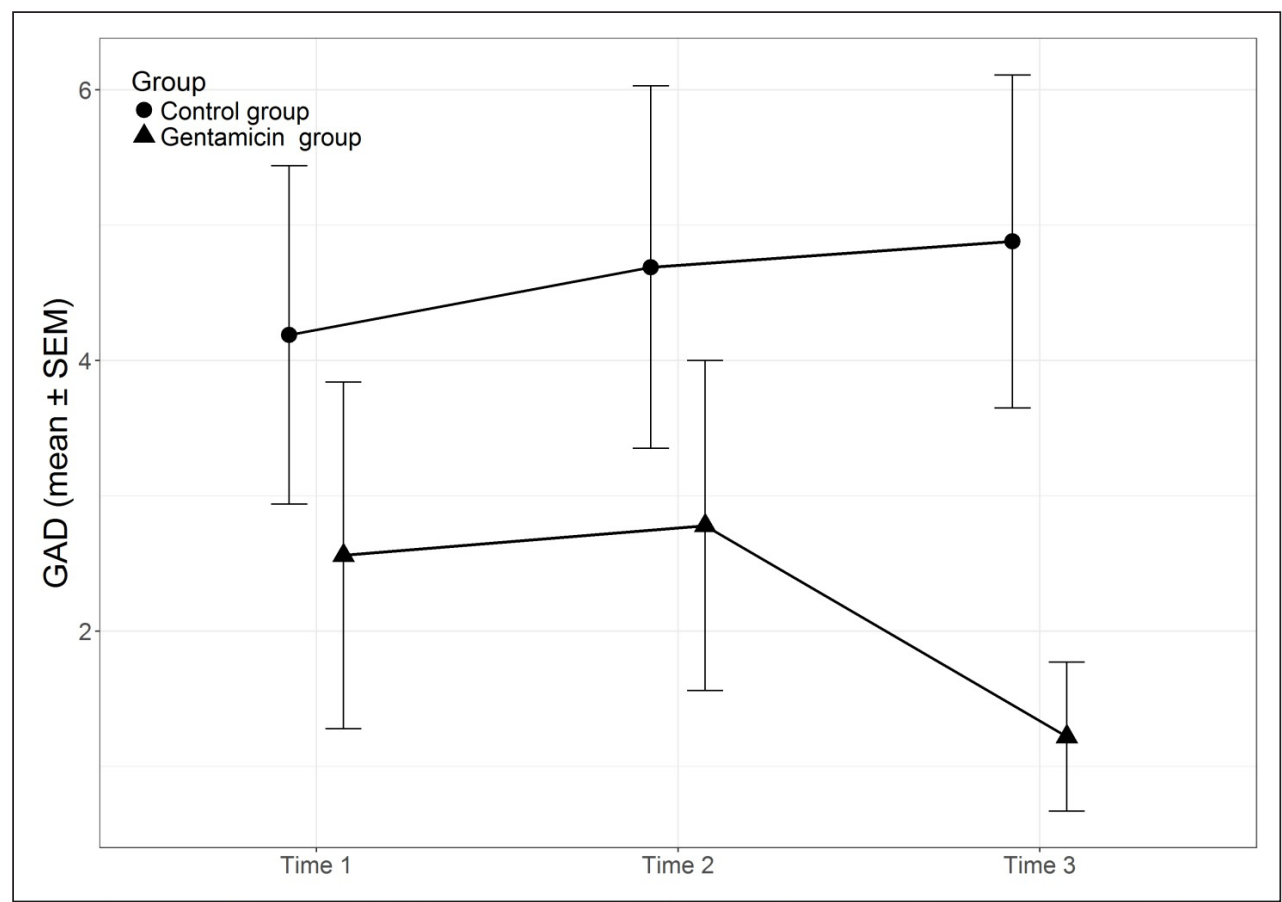

Fig. 1. Changes of GAD (mean \pm standard error of mean) in the gentamicin and the control group during the study period.

Time 1: 2 months before surgery, time 2: 2 weeks before surgery, after pretreatment in the gentamicin group, time 3: 3 months after surgery $(P=0.39)$.

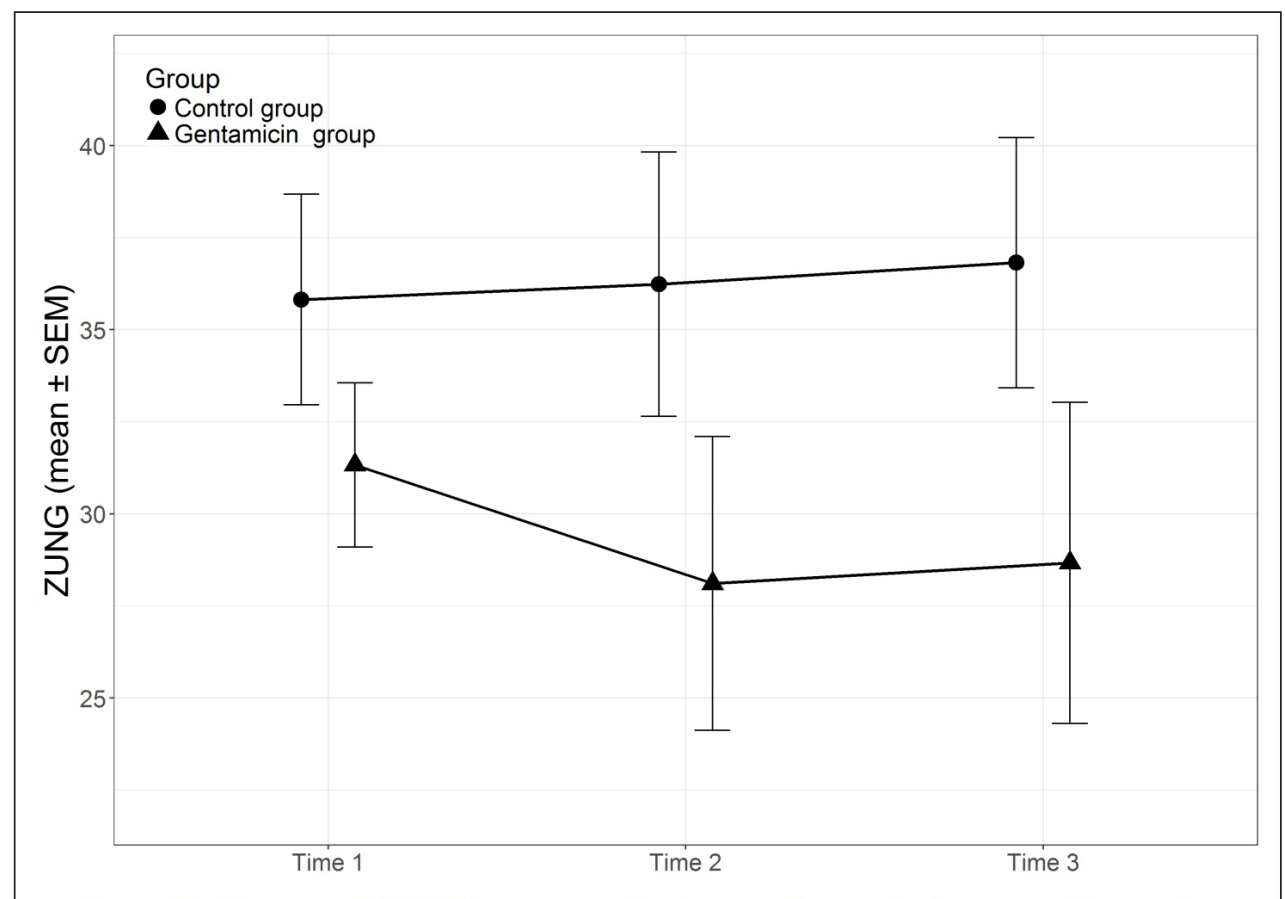

Fig. 2. Changes of the results from the ZUNG questionnaire (mean \pm standard error of mean) in the gentamicin and the control groups during the study period.

Time 1: 2 months before surgery, time 2: 2 weeks before surgery, after pretreatment in the gentamicin group, time 3: 3 months after surgery $(P=0.65)$. 
Table 3. Results - questionnaires.

\begin{tabular}{|c|c|c|c|c|c|c|}
\hline & & Gentan & in group & Con & I group & \\
\hline & & mean $(\mathrm{SD})$ & $P$-value ${ }^{\mathrm{w}}$ & mean (SD) & $P$-value ${ }^{\mathrm{w}}$ & $P$-value ${ }^{\mathrm{b}}$ \\
\hline GAD & time 1 & $2.56(3.84)$ & $P^{1,2}=0.581$ & $4.19(5.00)$ & $P^{1,2}=0.339$ & 0.454 \\
\hline & time 2 & $2.78(3.67)$ & $P^{2,3}=0.273$ & $4.69(5.36)$ & $P^{2,3}=0.888$ & 0.404 \\
\hline & time 3 & $1.22(1.64)$ & $P^{1,3}=0.345$ & $4.88(4.91)$ & $P^{1,3}=0.387$ & 0.020 \\
\hline ZUNG & time 1 & $31.33(6.69)$ & $P^{1,2}=0.246$ & $35.82(11.79)$ & $P^{1,2}=0.343$ & 0.500 \\
\hline & time 2 & $28.11(11.98)$ & $P^{2,3}=0.917$ & 36.24 (14.79) & $P^{2,3}=0.836$ & 0.145 \\
\hline & time 3 & $28.67(13.09)$ & $P^{1,3}=0.553$ & $36.82(14.01)$ & $P^{1,3}=0.221$ & 0.117 \\
\hline DHI & time 1 & $12.20(13.93)$ & $P^{1,2}=0.438$ & $20.13(21.86)$ & $P^{1,2}=0.221$ & 0.451 \\
\hline & time 2 & $15.40(13.37)$ & $P^{2,3}=0.672$ & $31.73(25.29)$ & $P^{2,3}=0.861$ & 0.164 \\
\hline & time 3 & $18.60(21.87)$ & $P^{1,3}=0.484$ & $35.87(25.84)$ & $P^{1,3}=0.068$ & 0.191 \\
\hline DHI score E & time 1 & $2.00(2.49)$ & $P^{1,2}=0.336$ & $5.73(6.32)$ & $P^{1,2}=0.180$ & 0.198 \\
\hline & time 2 & $3.40(4.33)$ & $P^{2,3}=0.348$ & $9.07(7.28)$ & $P^{2,3}=0.893$ & 0.067 \\
\hline & time 3 & $5.40(8.85)$ & $P^{1,3}=0.348$ & $10.13(7.65)$ & $P^{1,3}=0.027$ & 0.214 \\
\hline DHI score $\mathbf{P}$ & time 1 & $4.20(5.37)$ & $P^{1,2}=0.416$ & $4.93(5.18)$ & $P^{1,2}=0.302$ & 0.427 \\
\hline & time 2 & $5.40(4.81)$ & $P^{2,3}=0.397$ & $7.60(7.38)$ & $P^{2,3}=0.959$ & 0.634 \\
\hline & time 3 & $4.20(6.43)$ & $P^{1,3}=1.000$ & $8.53(7.27)$ & $P^{1,3}=0.104$ & 0.232 \\
\hline DHI score $\mathrm{F}$ & time 1 & $6.00(6.73)$ & $P^{1,2}=0.726$ & $9.47(11.02)$ & $P^{1,2}=0.257$ & 0.613 \\
\hline & time 2 & $6.60(5.89)$ & $P^{2,3}=0.340$ & $15.07(12.58)$ & $P^{2,3}=0.861$ & 0.125 \\
\hline & time 3 & $9.00(9.10)$ & $P^{1,3}=0.287$ & $17.20(12.39)$ & $P^{1,3}=0.046$ & 0.099 \\
\hline GBI total & time 2 & $3.92(5.75)$ & $P^{2,3}=0.203$ & - & - & - \\
\hline & time 3 & $8.02(11.82)$ & - & $-6.55(14.84)$ & - & 0.039 \\
\hline GBI general & time 2 & $-2.46(11.34)$ & $P^{1,2}=0.340$ & - & - & - \\
\hline & time 3 & $0.46(18.33)$ & - & $-16.67(17.83)$ & - & 0.046 \\
\hline GBI social & time 2 & $36.67(25.82)$ & $P^{1,2}=0.785$ & - & - & - \\
\hline support & time 3 & $40.74(40.06)$ & - & $39.29(22.27)$ & - & 0.772 \\
\hline GBI physical & time 1 & $-3.33(17.21)$ & $P^{1,2}=0.157$ & - & - & - \\
\hline & time 2 & $5.56(26.35)$ & - & $-11.9(20.07)$ & - & 0.051 \\
\hline GHSI total & time 1 & $64.03(13.39)$ & $P^{1,2}=0.028$ & $57.18(15.87)$ & $P^{1,2}=0.062$ & 0.264 \\
\hline score & time 2 & $60.83(11.30)$ & $P^{2,3}=0.192$ & 48.18 (10.7) & $P^{2,3}=0.734$ & 0.014 \\
\hline & time 3 & $56.23(15.36)$ & $P^{1,3}=0.017$ & $46.16(10.44)$ & $P^{1,3}=0.033$ & 0.093 \\
\hline GHSI general & time 1 & $64.38(16.42)$ & $P^{1,2}=0.058$ & $55.93(19.56)$ & $P^{1,2}=0.091$ & 0.333 \\
\hline subscale score & time 2 & $60.83(14.53)$ & $P^{2,3}=0.108$ & $45.55(15.92)$ & $P^{2,3}=0.752$ & 0.028 \\
\hline & time 3 & $52.88(21.71)$ & $P^{1,3}=0.030$ & $42.60(15.74)$ & $P^{1,3}=0.056$ & 0.153 \\
\hline GHSI social & time 1 & $59.17(9.98)$ & $P^{1,2}=0.317$ & $61.31(9.02)$ & $P^{1,2}=0.206$ & 0.693 \\
\hline support score & time 2 & $60.00(9.46)$ & $P^{2,3}=0.317$ & $58.33(11.24)$ & $P^{2,3}=0.414$ & 0.717 \\
\hline & time 3 & $63.33(8.96)$ & $P^{1,3}=0.236$ & $57.37(12.05)$ & $P^{1,3}=0.131$ & 0.166 \\
\hline GHSI physical & time 1 & $67.50(23.06)$ & $P^{1,2}=0.038$ & $58.04(21.71)$ & $P^{1,2}=0.009$ & 0.374 \\
\hline health score & time 2 & $61.67(19.72)$ & $P^{2,3}=0.786$ & $48.96(16.10)$ & $P^{2,3}=0.564$ & 0.129 \\
\hline & time 3 & $62.50(24.30)$ & $P^{1,3}=0.465$ & $49.04(16.51)$ & $P^{1,3}=0.137$ & 0.177 \\
\hline SVV & time I & $0.00(0.00)$ & $P$ I vs II $=0.066$ & $0.00(0.00)$ & $P$ I vs II $=0.066$ & 1.000 \\
\hline & time II & $2.50(4.09)$ & $P$ II vs III $=0.180$ & $1.33(1.72)$ & $P$ II vs III $=0.141$ & 0.911 \\
\hline & time III & $0.00(0.00)$ & $P \mathrm{I}$ vs III $=1.000$ & $0.92(1.75)$ & $P \mathrm{I}$ vs $\mathrm{III}=0.317$ & 0.152 \\
\hline $\mathrm{Ny}$ & time I & $0.00(0.00)$ & $P \mathrm{I}$ vs $\mathrm{II}=0.317$ & $0.08(0.28)$ & - & 0.358 \\
\hline & time II & $0.11(0.33)$ & $P \mathrm{II}$ vs III $=1.000$ & - & - & - \\
\hline & time III & $0.10(0.32)$ & $P$ III vs IV $=0.317$ & $0.38(0.51)$ & $P$ III vs IV $=0.564$ & 0.132 \\
\hline & time IV & $0.00(0.00)$ & $P$ I vs IV $=1.000$ & $0.25(0.45)$ & $P \mathrm{I}$ vs $\mathrm{IV}=0.157$ & 0.096 \\
\hline
\end{tabular}

SD - standard deviation; $P$-value ${ }^{\mathrm{w}}$ - within-group differences tested by Wilcoxon signed rank test; $P^{1,2}-P$-value of the difference between Time 1 and Time 2; $P^{2,3}-P$-value of the difference between Time 2 and Time $3 ; P^{3,1}-P$-value of the difference between Time 1 and Time $3 ; P$ I vs II $P$-value of the difference between Time I and II; $P$ II vs III - $P$-value of the difference between Time II and III; $P$ I vs III - $P$-value of the difference between Time I and III; $P$ III vs IV - $P$-value of the difference between Time III and IV; $P$ I vs IV - $P$-value of the difference between Time I and IV; $P$-value ${ }^{\mathrm{b}}$ - between-group differences tested by Mann-Whitney U test. ZUNG, GAD, DHI, GBI and GHSI questionnaires 2 months preoperatively (time 1), two weeks before the surgery after gentamicin instillation preoperatively (time 2), and 3 months postoperatively (time 3 ). Time I=time 1, time II=time 2, time IV=time 3 and time III (2 weeks postoperatively). Ny-nystagmus, SVV-subjective visual vertical, DHI-Questions are designed to incorporate functional (F), physical (P), and emotional (E) impacts on disability. 


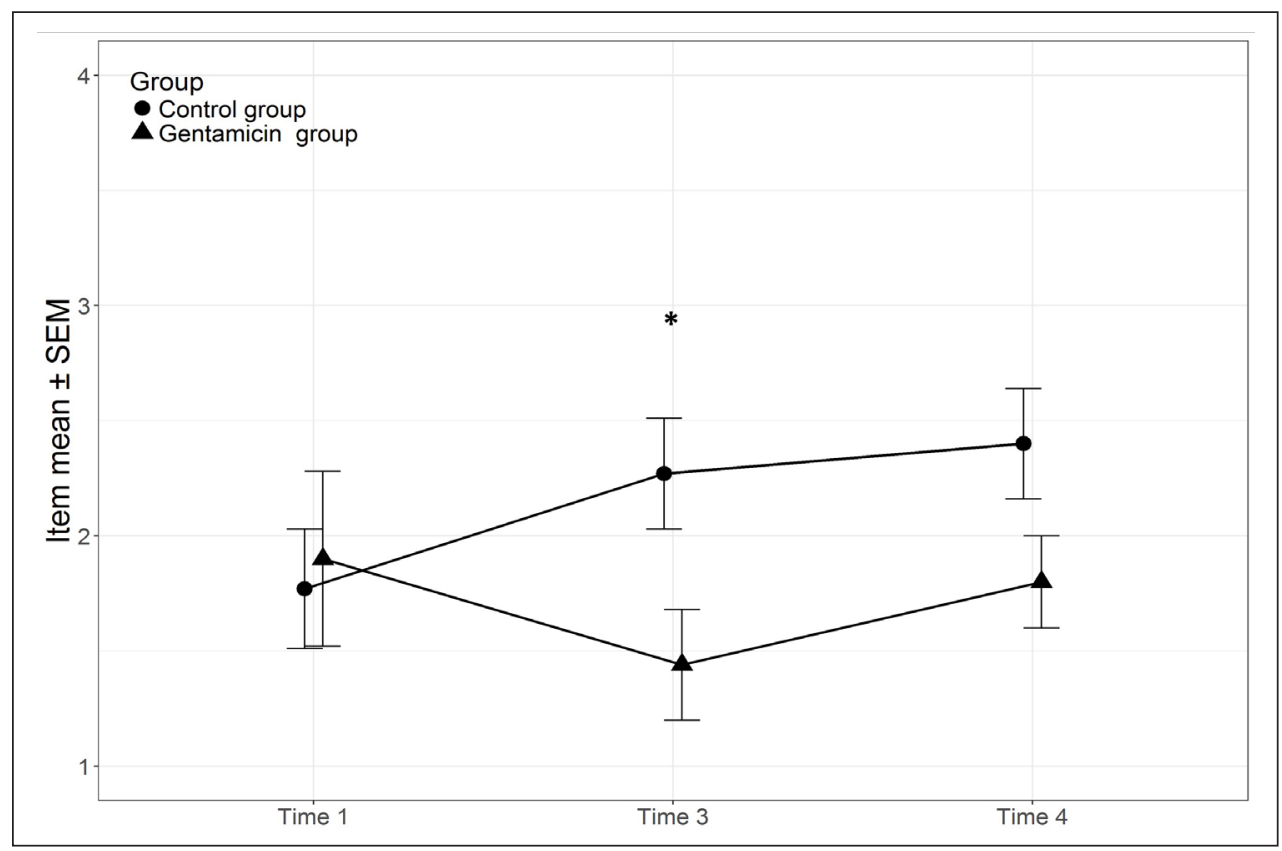

Fig. 3. Means and SEM for question 1: Do you have instability with, or does faster rotational motion bother you (e.g. rotates head from side to side when crossing the road)?

Time 1: 2 months before surgery, time 3: 3 months after surgery, time 4: 12 months after surgery. Significant differences between the gentamicin and the control group within a particular time are denoted by an asterisk (*: $P<0.05)$.

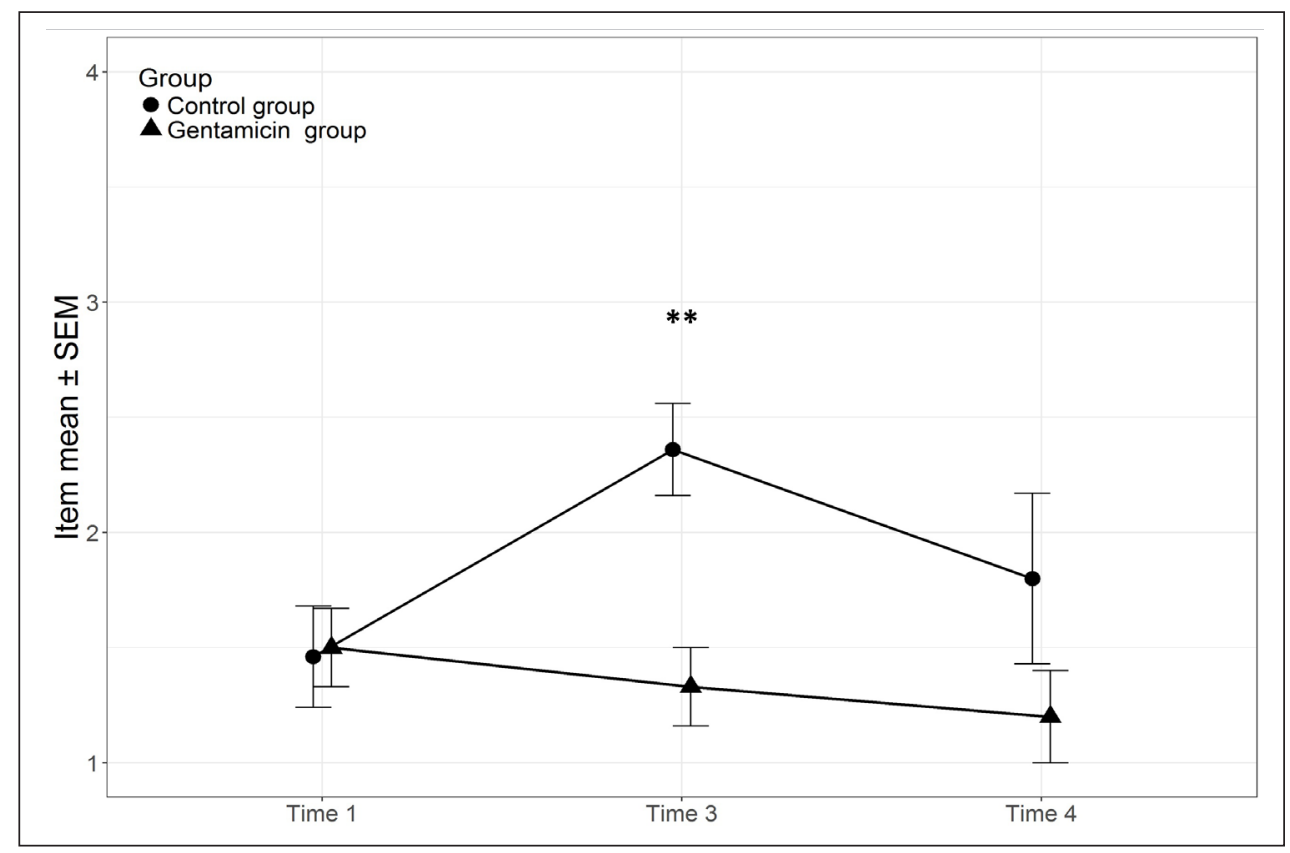

Fig. 4. Means and SEM for question 3: Do you have instability with, or does quickly changing position bother you (e.g. lying on a bed / getting up / recumbent)?

Time 1: 2 months before surgery, time 3: 3 months after surgery, time 4: 12 months after surgery. Significant differences between the gentamicin and control group within a particular time are denoted by the asterisks $(* *: P<0.01)$. 
Wilcoxon signed-rank test for testing inter-group differences and intra-group differences, respectively. $P$-values less than 0.05 were considered to be statistically significant. Statistical analyses were performed using the SPSS version 23 (SPSS Inc., Chicago, IL, USA) statistical software.

The study was approved by the institutional ethics committee of the University Hospital Motol and was performed in accordance with the principles of the 1983 Declaration of Helsinki. All patients provided informed consent prior to commencement of the study.

\section{RESULTS}

Age, sex and size of tumour did not differ in the gentamicin and control groups $(P>0.05)$. Complete tumour removal was achieved in all patients in the study. All patients in the gentamicin group had positive clinical head impulse tests, after instillation of 3 gentamicin doses. Vestibular loss was also evaluated by caloric bi-thermal testing and side differences moved within range from 75 $90 \%$. All patients suffered from postural instability after gentamicin application, usually one week after instillation, and no patient had spontaneous nystagmus.

No statistical differences were found between the control and gentamicin group in the DHI, GAD -7 (Fig. 1) and ZUNG test (Fig. 2) results (Table 3). The significant change in GHSI total score and in GHSI general subscale score in time 2 documents the effect of application of gentamicin. Results of the GBI questionnaire and its subscales, except for social subscore, were significantly better in the gentamicin group, which showed milder deterioration or even improvement of health status when compared to the control group.

Also, in questionnaires focused on anxiety (GAD) and depression (ZUNG), better results were observed in the gentamicin group than in the control group. Significantly better results in the gentamicin group $(P=0.02)$ were found in the GAD-7 survey in time 3.

Gentamicin pre-treated patients were significantly less sensitive to dynamic change in position of the head and body and also to visual stimulation, as documented by low scoring in questions $1,3,4$ and 8 (statistically significant $P<0.05$, Fig. 3,4). The gentamicin group was also more resistant to optokinetic stimulation $(P=0.065)$. Subjective visual vertical results were more abnormal in the gentamicin group than in the control group one week after the surgery, but patients showed better results on the long-term horizon. Similar results were observed in spontaneous nystagmus. Its presence was detected using electronystagmography.

Another quotable finding was revealed in results of optokinetic gain in time II (shortly before surgery and after instillation of gentamicin). Gentamicin pre-treated patients had significantly higher gain in speed at 30, 40, and 50 degrees in both directions when compared with the control group Importantly, we did not observe spontaneous nystagmus in either (Table 4). Deafferentation of labyrinth led to an increase in gain in both groups. Gain remained stable three months after the surgery.

\section{DISCUSSION}

The aim of chemical prehabituation is to achieve compensation before surgery, as surgical trauma triggers stress responses of the organism and might lead to further injury of vestibular centres. Separation of these two traumas into different time periods so they are not concurrent is helpful in improving the process of compensation. Presurgical chemical ablation of vestibular function on the side of the tumour leads to faster vestibular compensation ${ }^{18,19}$.

With this knowledge, we could assume that results of the GHSI, GBI, DHI total scores and the additional nine-question questionnaire would be different between

Table 4. Results - optokinetic gain.

\begin{tabular}{cc:cccc|ccc}
\hline & & \multicolumn{4}{c}{ Gentamicin group } & \multicolumn{3}{c}{ Control group } \\
Side & Speed & Time I & Time II & Time III & Time IV & Time II & Time III & Time IV \\
& & mean (SD) & mean (SD) & mean $(\mathrm{SD})$ & mean (SD) & mean (SD) & mean (SD) & mean (SD) \\
\hline left & 10 & $0.63(0.21)$ & $0.64(0.21)$ & $0.56(0.11)$ & $0.56(0.23)$ & $0.33(0.28)$ & $0.75(0.48)$ & $0.64(0.34)$ \\
& 20 & $0.46(0.20)$ & $0.42(0.17)$ & $0.41(0.16)$ & $0.44(0.22)$ & $0.26(0.15)$ & $0.33(0.30)$ & $0.45(0.25)$ \\
& 30 & $0.33(0.19)$ & $0.44(0.17)$ & $0.26(0.14)$ & $0.32(0.18)$ & $0.18(0.10)$ & $0.27(0.15)$ & $0.34(0.22)$ \\
& 40 & $0.24(0.18)$ & $0.30(0.07)$ & $0.17(0.13)$ & $0.27(0.18)$ & $0.16(0.20)$ & $0.20(0.19)$ & $0.22(0.16)$ \\
& 50 & $0.15(0.13)$ & $0.19(0.09)$ & $0.07(0.08)$ & $0.20(0.17)$ & $0.04(0.03)$ & $0.13(0.13)$ & $0.15(0.15)$ \\
right & 10 & $0.43(0.30)$ & $0.60(0.26)$ & $0.55(0.21)$ & $0.84(0.33)$ & $0.48(0.26)$ & $0.57(0.47)$ & $0.62(0.17)$ \\
& 20 & $0.54(0.23)$ & $0.46(0.14)$ & $0.43(0.12)$ & $0.52(0.20)$ & $0.28(0.18)$ & $0.28(0.12)$ & $0.52(0.27)$ \\
& 30 & $0.39(0.24)$ & $0.35(0.13)$ & $0.34(0.21)$ & $0.34(0.16)$ & $0.17(0.08)$ & $0.18(0.21)$ & $0.30(0.16)$ \\
& 40 & $0.13(0.14)$ & $0.36(0.14)$ & $0.29(0.19)$ & $0.22(0.11)$ & $0.10(0.08)$ & $0.13(0.14)$ & $0.22(0.12)$ \\
& 50 & $0.16(0.26)$ & $0.25(0.14)$ & $0.08(0.15)$ & $0.20(0.11)$ & $0.02(0.04)$ & $0.03(0.06)$ & $0.10(0.10)$ \\
\hline
\end{tabular}

SD - standard deviation; Time I (2 months preoperatively), time II (two weeks before the surgery after gentamicin instillation postoperatively), time III ( 2 weeks after the surgery) and in time IV ( 3 months postoperatively).

Time I=time 1 , time II=time 2 , time IV=time 3 and time III (2 weeks postoperatively). 
the gentamicin and control groups. GHSI scores in time 2 were significantly higher in the gentamicin pre-treated group. The total score in the gentamicin group was 60.83 and in the control group was $48.18(P=0.014)$. The general subscale score in the gentamicin group was 60.83 and in the control group was $45.55(P=0.028)$. The GBI total score, general subscale score and physical subscore showed significantly better results in the gentamicin group. In time 3, patients in the gentamicin group showed positive scores, whereas we observed negative scores in the control group, that indicates deterioration of the health status. These results agree with previous findings ${ }^{9}$, with the exception of the DHI score. Gentamicin pretreated patients recorded a better DHI score in time 2 and 3 , which was, however, not statistically significant $(P=0.164$ and $P=0.191)$.

There was an increase of the DHI score from 12.2 (time 1) to 15.4 (time 2) after gentamicin treatment. This score was not further influenced by the surgery and remained almost stable at 18.6. In the control group the DHI score changed between time 1 to time 2 (no intervention) from 20.13 to 31.73 , and the score later increased to 35.87 . This result might be affected by the relatively small size of the study. Although the method of clinical selection of patients for the sample group was used in this study in order to respect ethical norms, the multi-factorial method used in our analysis ultimately showed that the method of selection did not affect the results. Another factor might be that the DHI questionnaire, which was created for all possible types of vestibular disorders, might not be ideal for examining this specific condition. Results in the gentamicin group can be explained as an onset of vestibular failure following gentamicin application, prior to surgical neurectomy ${ }^{8}$. After the surgery, there is only minor deterioration in the pre-treatment group. In the long-term follow-up, these differences in score remained stable in this study, but the findings are not statistically significant ${ }^{9}$.

Vestibular compensation is a complicated process, which includes adaptation to sudden labyrinth failure and leads to substitution of missing vestibular information by other senses, changes in the postural strategy, and behavioural adaptations $s^{9,20}$. The preoperative degree of failure of labyrinth function, as well as psychological, social and other factors are studied as factors influencing the final level of handicap after sudden vestibular loss, including vestibular neurectomy $y^{3,21,22}$.

Even though we did not find a statistically significant difference between the two groups in the GAD and ZUNG questionnaires, it is obvious that the gentamicin group patients had lower scores in all studied time periods. It seems as if they were naturally more resilient to anxiety and depression (Fig. 1,2). We can consider the effect of other postsurgical neurological deficits (facial nerve palsy, trigeminal palsy) on overall psychological status, but only mild to moderate facial nerve lesions and no trigeminal nerve palsy were observed. Furthermore, the difference between both groups was observed prior to the surgery, when there was no neurological deficit yet present. Postoperative social support was perceived as significantly greater in the control group in our study. We can speculate that this difference could be due to the presence of a more debilitating postsurgical handicap, which demanded higher levels of support from family and caregivers. This point seems worthy of further elucidation during future follow-up visits. Nevertheless, this difference does not translate into an overall handicap or resultant functional restoration, as seen in other examined scores. On the contrary, the postoperative DHI score in the control group shows a tendency towards a greater handicap, even though social support is perceived as higher.

We found significant differences in specific questions in our questionnaire and specifically in those which were focused on sensitivity to optic flow and quick rotational movements of the head and body (questions 1, 3, 4, 6, 8) (Fig. 3,4). It supports our thesis that prehabituation has a positive impact on management of vestibular function. In our study, patients performed vestibular exercises according to an instructional booklet, without supervision from a physiotherapist. It is known that patient motivation and supervision by physiotherapist are key to achieving a positive effect in vestibular rehabilitation, and thus this reality may have influenced the outcome ${ }^{7}$. Unlike in other studies ${ }^{8}$, we have never achieved total areflexia in our study, even after repeated application of gentamicin. It should be noted that the surgical approach was different in these studies (translabyrinthine vs. retrosigmoid approach), which could be the reason for the divergent outcomes.

We found out in our previous study that patients showed higher resistance when exposed to optic flow. Optic flow is a type of three-dimensional optokinetic stimulation with an important emphasis on balance and movement perception ${ }^{23}$. This finding was confirmed by our study. Question 6 in our questionnaire showed an apparent difference between the gentamicin and control groups. Even though the result is not statistically significant, greater resiliency to combined sensorial loads was proved repeatedly in both our studies.

Baseline optokinetic nystagmus (OKN) gain in the control group was significantly lower than in the gentamicin patients, where it remained high even after the gentamicin application. After the neurectomy, there was a mild decrease of OKN gain in the gentamicin group and an increase in the control group. At the follow-up appointment three months after the surgery, OKN gain returned to baseline values in the gentamicin group and remained high in the control group. It seems that the superposition of latent nystagmus did not influence the results. If we compare results from both groups in time I (gentamicin group) with time II (controls), it means prior to any intervention, and results in time II (gentamicin group) with time III (controls), after the labyrinthectomy/neurectomy, there is no significant difference. That would indicate that the gain of optokinetic nystagmus was more influenced by central factors. This result supports our thesis.

We expected that OKN asymmetry, after vestibular loss due to gentamicin or neurectomy, would return to 
normal with compensation. This, however, was not observed in our study, and thus another explanation must be formulated. The most striking finding, in this respect, is in the low optokinetic response rate before surgery in the control group. We found previously that gentamicin pre-treated patients are more resilient to optic flow stimulation and have fewer subjective complaints ${ }^{9}$. In this study, lower levels of anxiety and depression were found in the gentamicin group than in the control group. We hypothesize that psychological factors play more important role in the modulation of optokinetic response dynamics than previously thought.

The anatomical substrate for these functional influences is created by connections between the central vestibular and limbic systems, particularly in the amygdala system ${ }^{24}$. Optokinetic gain was shown to increase significantly with anxiety and increased arousal, according to several reports $^{10,25,26}$. Disturbance of smooth pursuit performance is a known trait of schizophrenia and depression, and it has similar influence on optokinetic response ${ }^{27}$. Low gain of optokinetic nystagmus was reported in patients with panic disorder or depression ${ }^{28}$.

These findings led us to hypothesize that low baseline optokinetic gain in the control group is caused by the presence of depression and anxiety. Indeed, patients in the gentamicin group presented with lower levels of psychological discomfort and on the whole were less handicapped. These results further stress the importance of psychological factors in the final compensation after schwannoma surgery. Gentamicin prehabituation alters patient expectations before the operation and thereby reduces the level of postoperative anxiety.

\section{CONCLUSION}

Vestibular prehabituation with preoperative gentamicin ablation of vestibular function combined with vestibular rehabilitation does not significantly improve quality of life, from the view of stability. The change of general postoperative status in the gentamicin group was perceived as significantly better. Patients prehabituated with gentamicin were significantly more resilient to combined sensorial input. It also helped them to lower levels of anxiety in the postoperative period and it helped them to recover more effectively after the operation. Psychological factors play a key role in process of compensation of vestibular dysfunction after schwannoma surgery.

Acknowledgement: The authors declare that they received no financial support from any other third party. Supported by PROGRES Q28, UNCE 204013, GAUK 310216, and the Ministry of Health of the Czech Republic, grant No. NV18-08-00229. All rights reserved.

Author contributions: ZB, ZC: contributed equally to this work.

Conflict of interest statement: The authors state that there are no conflicts of interest regarding the publication of this article.

\section{REFERENCES}

1. Betka J, Zvěřina E, Balogová Z, Profant O, Skřivan J, Kraus J, Lisý J, Syka J, Chovanec M. Complications of microsurgery of vestibular schwannoma. Biomed Res Int 2014; 2014:315952. doi: 10.1155/2014/315952

2. Teggi R, Franzin A, Spatola G, Boari N, Picozzi P, Bailo M, Piccioni LO, Gagliardi F, Mortini P, Bussi M. Vestibular assessment in patients with vestibular schwannomas: what really matters? Acta Otorhinolaryngol Ital 2014;34:123-8.

3. Herdman SJ, Clendaniel RA, Mattox DE, Holliday MJ, Niparko JK. Vestibular adaptation exercises and recovery: acute stage after acoustic neuroma resection. Otolaryngol Head Neck Surg 1995;113:77-87. doi:10.1016/S0194-59989570148-6

4. Furman MJ, Balaban CD, Pollack IF. Vestibular compensation in a patient with a cerebellar infarction. Neurology 1995;48:916-20.

5. Parietti-Winkler C, A. Lion A, J. Frére J, Perrin PP, Beurton R, Gauchard GC. Prediction of balance compensation after vestibular schwannoma surgery. Neurorehabil Neural Repair 2016;30:395-401. doi: $10.1177 / 1545968315600270$

6. Čakrt O, Chovanec M, Funda T, Kalitová P, Betka J, Zverina E, Kolár $P$, Jerábek J. Exercise with visual feedback improves postural stability after vestibular schwannoma surgery. Eur Arch Otorhinolaryng 2010;267:1355-60.

7. Cohen HS, Kimball KT, Jenkins HA. Factors affecting recovery after acoustic neuroma resection. Acta Oto-Laryngologica 2002;122:84150.

8. Magnusson M, Kahlon B, M. Karlberg M, Lindberg S, Siesjö P. Preoperative vestibular ablation with gentamicin and vestibular 'prehab' enhance postoperative recovery after surgery for pontine angle tumours - first report. Acta Oto-Laryngologica 2007;127:123640. doi: 10.1080/00016480701663433

9. Čada Z, Balatková Z, Chovanec M, Čakrt O, Hrubá S, Jeřábek J, Zvěřina E, Profant O, Fík Z, Komarc M, Betka J, Kluh J, Černý R. Vertigo Perception and Quality of Life in Patients after Surgical Treatment of Vestibular Schwannoma with Pretreatment Prehabituation by Chemical Vestibular Ablation. Biomed Res Int 2016;2016:767216. doi: 10.1155/2016/6767216

10. Monzani D, Marchioni D, Bonetti S, Pellacani P, Casolari L, Rigatelli M, Presutti L. Anxiety affects vestibulospinal function of labyrinthinedefective patients during horizontal optokinetic stimulation. Acta Otorhinolaryngol Ital 2004;24:117-24.

11. Jacob RG, Redfern MS, Furman JM. Space and motion discomfort and abnormal balance control in patients with anxiety disorders. J Neurol Neurosurg Psychiatry 2009;80:74-8. doi: 10.1136/jnnp.2007.136432

12. Staab JP. Chronic dizziness: the interface between psychiatry and neuro-otology. Curr Opin Neurol 2006;19:41-8.

13. Swinson RP. The GAD-7 scale was accurate for diagnosing generalised anxiety disorder. Evid Based Med 2006;11:184. doi. 10.1136/ ebm.11.6.184

14. Spitzer RL, Kroenke K, Williams JB, Löwe B. A brief measure for as sessing generalized anxiety disorder: the GAD-7. Arch Intern Med 2006;166:1092-7. doi: 10.1001/archinte.166.10.1092

15. Zung WWK. A Self-Rating Depression Scale. Arch Gen Psychiatry 1965;12:63-70.

16. Robinson K, S. Gatehouse S, Browning GG. Measuring patient benefit from otorhinolaryngological surgery and therapy. Ann Otol Rhinol Laryngol 1996;80:415-22. doi: 10.1177/000348949610500601

17. Jacobson GP, Newman CW. The development of the Dizziness Handicap Inventory. Arch Otolaryngol Head Neck Surg 1990;116:424-7.

18. Tjernström F, Fransson PA, Kahlon B, Karlberg M, Lindberg S, Siesjö $P$, Magnusson M. Vestibular prehab and gentamicin before schwannoma surgery may improve long-term postural function. Journal of Neurology, Neurosurgery and Psychiatry 2009;80:1254-60. doi: 10.1136/jnnp.2008.170878

19. Tjernström F, Fransson PA, Kahlon B, Karlberg M, Lindberg S, Siesjö $P$, Magnusson M. Hearing and Vestibular Function After Preoperative Intratympanic Gentamicin Therapy for Vestibular Schwanomma as Part of Vestibular Prehab. Ear and Hear 2016;37:744-50. doi: 10.1097/ AUD.0000000000000340

20. Lacour M, Bernard-Demanze L. Interaction between Vestibular Compensation Mechanisms and Vestibular Rehabilitation Therapy: 10 Recommendations for Optimal Functional Recovery. Front Neurol 2015;5:285. doi: 10.3389/fneur.2014.00285 
21. Han BI, Song HS, Kim JS. Vestibular rehabilitation therapy: review of indications, mechanisms, and key exercises. J Clin Neurol 2011;7:184-96. doi: 10.3988/jcn.2011.7.4.184

22. Zaback M, Cleworth TW, Carpenter MG, Adkin AL. Personality traits and individual differences predict threat-induced changes in postural control. Hum Mov Sci 2015;40:393-409. doi: 10.1016/j. humov.2015.01.015

23. O'Connor KW, P. J. Loughlin PJ, M. S. Redfern MS, Sparto PJ. Postural adaptations to repeated optic flow stimulation in older adults. Gait Posture 2008;28:385-391. doi: 10.1016/j.gaitpost.2008.01.010

24. Balaban CD, Tahyer JF. Neurological bases for balance-anxiety links. J Anxiety Disord 2001;15:53-79.

25. Naranjo EN, Cleworth TW, Allum JH, Inglis JT, Lea J, Westerberg
BD, Carpenter MD. Threat effects on human oculo-motor function. Neuroscience 2017;359:289-98. doi: 10.1016/j.neuroscience.2017.07.024

26. Magnusson M, Pyykkö I, Jantti V. Effects of alertness and visual attention on nystagmus in humans. Am J Otolaryngol 1985;6:419-25.

27. Benson PJ, Beedie SA, Shephard E, Giegling I, Rujescu D, St Clair D. Simple Viewing Tests Can Detect Eye Movement Abnormalities That Distinguish Schizophrenia Cases from Controls with Exceptional Accuracy. Biol Psychiatry 2012;72:716-24. doi: 10.1016/j.biopsych.2012.04.019

28. Jergelova M, Jagla F. Central and peripheral correlates of eye movements in selected mood disorders. Neuro Endocrinol Lett 2010;31:731-7. 